\title{
Nursing's Role with cervical cancer screening in Upper Egypt
}

Howieda Fouly, MSN, Assistant Lecturer of Obstetrics \& Gynecology Nursing Faculty of Nursing, Assiut University

Marilyn Stringer, PhD, WHNP-BC, FAAN University of Pennsylvania

Atef Darwish, PhD, MD, Professor of Obstetrics \& Gynecology, Faculty of Medicine Assiut University Assiut

Dalal Eshra, PhD, Professor of Obstetrics \& Gynecology Nursing , Faculty of Nursing Monofia University.

Monofia Egypt

Sahar Naguib, PhD, Professor of Obstetrics \& Gynecology, Faculty of Nursing, Assiut University,Egypt.

Mohamed Galal PhD, MD, Professor of Pathology, Faculty of Medicine, Assiut University,Egypt.

\begin{abstract}
:
Women in developing countries face many barriers that prevent them from receiving adequate, timely cervical cancer screening. In Egypt the prevalence of cervical cancer was 7.8/100,000 with 2713 newly annual reported cases. Objectives: to increase women's awareness of cervical cancer risk using counseling and to determine nursing's role in the screening tests. Methods: A cross sectional design, of non-pregnant, non-virginal women was recruited. Results: 450 non-pregnant women were counseled and consented for screening. The nurse was able to identify squamous columnar junction $100 \%$. In comparing positive visual inspection with acetic acid (VIA) to pap smear screening results, findings were $17.1 \%$ $(\mathrm{n}=77)$ and $5.1 \%(\mathrm{n}=68)$, respectively. In comparing negative VIA to pap smear screening results, findings were $82.9 \%(n=373)$ and $83.8 \%(n=377)$, respectively. Conclusion: Nurse's performing VIA is as effective screening tool for determining precancerous or cancerous cervical lesions.
\end{abstract}

Key words : Cervical cancer, Visual Inspection with Acetic Acid (VIA), Nurse's Role, Cancer screening, Counseling

\section{Introduction:}

In Egypt, the impact of cancers is unknown, as national databases do not track female genital cancer. Therefore, there is lacking of resources to support a population-based cancer registration system. The prevalence of cervical cancer is the main source of cancer statistics (Amr et al., 1999). The incidence of cervical cancer for Egypt reported to WHO, is based on one cancer registry survey conducted in Gharbiah governorate 2002 and did not include all Egyptian governorates. The incidence of cervical cancer is $1.3 / 100,000$ when compared to other women's cancers in Egypt as This incidence places cervical cancer as the $13^{\text {th }}$ ranked among other types of cancers (IARC 2008, WHO/ICO 2010).

Systematic screening programs using cervical cytology or Pap smear testing is considered the optimum strategy to reduce cervical cancer incidence in developed countries. However, an organized screening program is difficult to implement in developing countries where resources are limited. A number of cervical cancer screening approaches as alternatives to cervical cytology have been evaluated including automated PAP screening, visual inspection with acetic acid (VIA) testing, human papillomavirus virus testing and the polar probe testing. Among these, VIA, is the least expensive screen and is of great interest to developing countries as the screen requires only locally accessible supplies, preformed proficiently and performed by non-physicians with proper training (Germar \& Merialdi, 2005).

In developing countries VIA is the preferred screening test due to its low cost of technical requirements, the lack of available laboratory infrastructure and the inability for women to access frequent repeated testing. These reasons encouraged exploration of the feasibility of VIA screening programs in developing countries as research was needed to compare the performance characteristics of cytology and its potential alternatives (Sankaranarayanan et al., 2006). There is an important role of nurse in this study. The nursing profession can play a pivotal role in increasing the number of women who participate in cervical cancer screening. Barriers to screening include increased age, nonwhite race/ethnicity, low educational level, low income, decreased access, insufficient funding, and unfavorable attitudes toward screening (Hilton, et. al., 2003). Visual detection approaches of cervical cancer such as VIA has been around for a long time. The choice of VIA screening test is due to its low cost of technical requirements, the lack of available laboratory infrastructure and the inability for women to

Vol , (1) No , (1) June 2013 
access frequent repeated testing. These reasons encouraged exploration of the feasibility of VIA screening programs in developing countries as research was needed to compare the performance characteristics of cytology and its potential alternatives. However when an alternative screen to cytology is selected such as VIA, emphasis should be placed on accurate observation and evaluation of the test procedures and outcomes. In developing countries existing ineffective cytology based programs should be crucially reorganized and studied to explore the best option for cervical cancer screening, diagnosis and treatment (Sankaranarayanan et al., 2006).

\section{Purpose:}

The purpose of this cross sectional design study is to increase women's awareness about cervical cancer risk using counseling, and to determine nursing's role in the screening tests of cervical cancer.

\section{Methodology:}

Sample: The convenience sample was estimated to be 450 of non-pregnant women recruited of 600 cases from the Gynecological outpatient clinic and Early Cancer Detection Unit at Women's Health Center in Assiut University hospitals. From July 2006 to August 2007. The inclusion criteria included women 1) 30 years of age or older 2) who experienced gynecological complaints 3) who were married, widowed or divorced 4) who had prior sexual intercourse experience.

\section{Data-Collection Procedure}

The simple explanation was used to enhance the women's understanding of the screening. Women received pelvic, Pap smears and visual inspection with acetic acid (VIA) examinations by a trained nurse. Afterwards these tests were compared for sensitivity and specificity. The positive cases referral to Colposcopy examination performed by "Physician". If the colposcopic test result was suspicious or "positive", a biopsy was performed for diagnosis and used as the reference test.

\section{Results:}

The mean age of study sample was $34.9 \pm 5.9$ years. Regarding residence, the majority 400 (88.9\%) of women were from rural areas, while only $50(11.1 \%)$ lived in urban areas. The majority of women were married or $5.8 \%$ widowed and only $1.5 \%$ were separated. The findings for multiple gynecological complaints showed that the majority $(89 \%)$ of women had vaginal discharge and the less common complaint $(19 \%)$ was bleeding after intercourse. The most of women suffered from multiple symptoms, so the table reflects more than one complaint per woman. The condition of the cervix observed by the nurse, illustrated in the following table 
Table 1. Nurse's visual observation of the cervix

\begin{tabular}{lll}
\hline Nurse's visual observation of the cervix & Frequency & Percent \\
\hline Healthy cervix (normal & 158 & 35 \\
Unhealthy cervix & 292 & 65 \\
\hline Total & $\mathbf{N}=\mathbf{4 5 0}$ & $\mathbf{1 0 0 \%}$ \\
\hline
\end{tabular}

Table 2. The Pap smear findings reported on laboratory reports. ( $N=450)$

\begin{tabular}{lll}
\hline Pap smear findings & Frequency $\boldsymbol{n}=$ & Percent $\%$ \\
\hline Non evidence malignant & 377 & 83.8 \\
Atypical cells & 46 & 10.2 \\
SIL Low grade & 18 & 4.0 \\
SIL High grade & 3 & 0.7 \\
Squamous cell cancer & 1 & 0.2 \\
Unsatisfactory sample & 5 & 1.1 \\
\hline \multicolumn{1}{c}{ Total } & $\mathbf{4 5 0}$ & $\mathbf{1 0 0 \%}$ \\
\hline
\end{tabular}

Table 3. The incidence of positive and negativeVIA tests.

\begin{tabular}{llll}
\hline Diagnostic indices & VIA \& Pap smear & Pap smear Colposcopy \& & VIA \& Colposcopy \\
\hline Sensitivity (\%) & 59 & 54 & 70.6 \\
Specificity (\%) & 85.6 & 98.7 & 85.6 \\
PPV (\%) & 19.4 & 70.6 & 18 \\
NPV (\%) & 97.2 & 97.4 & 98.5 \\
Diagnostic accuracy*(\%) & 84.2 & 96.2 & 85 \\
LR * & $\mathbf{4 . 1}$ & $\mathbf{2 7}$ & $\mathbf{4 . 6}$ \\
\hline
\end{tabular}


Table 1: Two thirds of women $65 \%$ have had unhealthy cervix as ectopy, inflammation with hypertrophied, cervical polyps, ectropion and cervical congestion.

The findings of this study after receiving counseling, about the importance of cervical cancer screening, $100 \%(\mathrm{~N}=450)$ of the women agreed to have cervical cancer screening. The findings of Pap smear sample obtained by investigator (nurse) was $99.3 \%(n=445)$ satisfactory and $0.7 \%(n=5)$ unsatisfactory sample. Table 1 showed negative findings were defined as normal (no evidence of malignancy) findings. Positive findings were defined as SIL low grade was $4.0 \%(n=18)$, SIL high grade was $0.7 \%(n=3)$ and Squamous cell cancer was $0.2 \%(n=1)$. Based on the $2 \times 2$ table with cells a, b, c, d equal to $13,54,9,323$ the overall agreement measure equaled 323/399 or $80.9 \%$. Cohen's kappa $=.228$ with significance equaled $=.000$. McNemar's Test equaled 35.8 with significance equaled .000. Positive percent agreement (PPA) equaled $13 / 22$ or $59 \%$. The negative percent agreement $(\mathrm{NPA})=323 / 377$ or $85.6 \%$. In addition to, the findings of VIA test were defined as positive $17.1 \%(\mathrm{n}=77)$ and negative $82.9 \%$ $(n=373)$. See Tables $3 \& 4$

Table 3: As evidenced in the table below when determining sensitivity, we found that comparing VIA to the gold standard (colposcopy) was similar to the comparison of Pap smear to colposcopy with VIA compared to colposcopy versus Pap smear and colposcopy equaling $98.5 \%$ versus $97.4 \%$. In addition to, VIA as compared to colposcopy screening was good for ruling OUT precancerous/cancerous lesions in negative findings $(98.5 \%)$, but for ruling precancerous/cancerous lesions as only picks up $70.6 \%$ of time.

\section{Discussion:}

Nursing's role in counseling of cervical cancer Nurses have an important role in cervical cancer prevention through patient education, broadening their scope of practice to include cervical cancer screening and the performance of related cervical cancer research to improve patient outcomes. The study findings were consistent with other researchers and support these assumptions that indicated $100 \%$ of eligible women agreed to participate in the study after receiving comprehensive counseling. Other researchers demonstrated similar findings related to the effectiveness of nurses and nurse midwives providing cervical cancer counseling and screening. (Turkistanl, Sogukpınar, Saydam, \& Aydemir, 2003; Yücel, Çeber, \& Özentürkh, 2009) Nursing's role in the screening of cervical cancer
The VIA as an alternative method of cervical cancer screening. It was characterized by the simplicity in its technique, easily learned with appropriate training by such as nurses. In the current study, the provider was a highly educated nurse, who studied basic anatomy and physiology of the cervix and received one week of training on how to perform the VIA screening test. Other international researchers have demonstrated similar findings indicative of nurses safely expanding their scope of practice to include VIA screening as

demonstrated in the initial pioneering studies (Denny et al., 2000, University of Zimbabwe /JHPIEGO

Cervical Cancer Project 1999, Sankaranarayana 1997; Megevand 1996; Cecchini et al., 1993) and in more recent studies (Sarian et al., 2005; Muwonge et al., 2010). In all these studies, the nurse trained from 3-7 days on how to recognize normal and abnormal cervical conditions and the acetowhite lesion as a positive VIA screen. Along with these researchers, various other study groups trained nurses (Sarian et al., 2005; Muwonge et al., 2010) and paramedical personnel (Ahmed et al., 2008) to detect pre-cancerous conditions or evidence of cervical cancer among women patients, along with counseling, referral, follow-up and management of women. In addition, Murillo et al. 2010 had nurses perform the complete screening procedure including the cervical examination, VIA and Pap smear testing (Murillo et al., 2010).

VIA Compared To Pap Smear As Reference Test.

Using colposcopy as a standard reference for both VIA and Pap smear resulted in promising findings for using VIA as a screening test rather than the Pap smear. Sensitivity of VIA was $70.6 \%$ versus $54 \%$ for Pap smear and specificity of VIA was $98.7 \%$ versus $85.6 \%$ for Pap smear. In addition, PPV and NPV of VIA to Pap smear was $19.4 \%$ and $97.2 \%$ respectively; The PPV and NPV of VIA to colposcopy was $70.6 \%$ and $97.4 \%$, respectively and the PPV and NPV of Pap smear to colposcopy were $18 \%-98.5 \%$ respectively. According to these study comparisons, the findings of VIA were effective in detecting precancerous/ cancerous lesions. The VIA has better sensitivity, specificity and PPV when comparing VIA to Colposcopy versus Pap smear to colposcopy but similar NPV to Pap smear screening.

\section{Conclusion:}

In this study, the nurse succeeded in counseling women about the benefits of cervical cancer screening by dismaying the stigma associated with cervical cancer screening. This counseling resulted in the acceptance of screening for early detection of cervical cancer using visual inspection with acetic 
acid. The nurse demonstrated proficiency in the ability to successfully perform VIA and Pap smear screening and indicates also that VIA has a role in detection of cervical lesions that currently is not readily available in Egypt. In addition to VIA is an effective to detect precancerous/cancerous cervical lesions in a low resource setting with limited availability of cervical cancer screening.

\section{Acknowledges:}

We are grateful to Director and nurses at Early Detection of Cervical Cancer Clinic at Women's health center of University of Assiut in Egypt, for all facilities they introduced. Deep grateful too for University of Pennsylvania, School of Nursing to supportive work. Also great appreciation for all participants' women in this study.

\section{References:}

1. Ahmed, T., Ashrafun, N., Rahman, J. (2008).Development of a visual inspection programme for cervical cancer prevention in Bangladesh. Reproductive Health Matters, 16 (32), 78-85.

2. Amr, S.S., Bondy, M. L., Raouf, A. A., Moselhy, A. M., Dennis, A.J., \& Bernard L. (1999). Cancer mortality in Menofeia, Egypt: comparison with US mortality rates. Cancer Causes and Control, 10 (5), 349-354

3. Cecchini S, Bonardi R, Mazzotta A et al. (1993). Testing cervicography and cervicoscopy as screening tests for cervical cancer. Tumori 79:22-25

4. Denny, L., Kuhn, L., Pollack, A., et al. (2002). Direct visual inspection for cervical cancer Screening: an analysis of factors influencing test performance. Cancer, 94,1699-707

5. Germar, M-J. V., \& Merialdi, M. (2005). Report of a WHO Consultation. (UN published). Review prepared for The $12^{\text {th }}$ Postgraduate Course in Reproductive Medicine and Biology, Geneva Switzerland. accessed on 9/22/2004 http://www.gfmer.ch/Endo/course2003/ .

6. Hilton, L.W., Jennings-Dozier, K., Bradley, P.K., Lockwood-Rayermann, S., DeJesus, Y. Stephens, D.L., et al. (2003). The Role of Nursing in Cervical Cancer Prevention and Treatment, Second International Conference on Cervical Cancer. CANCER , 98(9 Suppl.), 20704.

7. International Agency for Research on Cancer (IARC), Globocan. (2008). (Specific methodology for Egypt: Simple mean of the incidence rates from Egypt, Aswan (1999-2003) and Egypt, Gharbiah (1999-2002) applied to the 2008. For further details, refer to www.who.int/hpvcenter

8. Megevand, E., Denny, L., Dehaeck, K., Soeters, R. \& Bloch, B. (2001). Acetic acid visualization of the cervix: an alternative to cytologic screening. Obstetrics and Gynecology. 88(3), 383-386.

9. Murillo, R., Gamboa, L.J., Osorio, O., E., \& Cendales, B.J. (2010). Cervical Cancer Screening Study Group. Cervical cancer screening with naked-eye visual inspection in Colombia. International Journal of Gynecology and Obstetrics, 109, 230-234.

10. Muwonge, R., Manuel, M., Antonio, P., Filipe, C., Dumas, J.B., Frank, M. R., \& Sankaranarayanan, R. (2010). Visual screening for early detection of cervical neoplasia in Angola. International Journal of Gynecology and Obstetrics, 111, 68-72

11. Ottaviano, M., La Torre, P. (2001). Examination of the cervix with the naked eye using acetic acid test. Am. J. of Obstetrics and Gynecology, 143, 139-142.

12. Sankaranarayanan R, Budukh AM \& Rajkumar R. (2001). Effective screening programmes for cervical cancer in low- and middle-income developing countries. Bulletin of the World Health Organization;79:954-962.

13. Sankaranarayanan R, Wesley R, Mathew B, Chandralekha B, Beegum A, Amma, N.S., et al. (1997). Evaluation of visual inspection as a screening test for cervical cancer. $\mathrm{Br} \mathrm{J}$ Cancer;75:436-40.

14. Sankaranarayanan R., Esmy, P.O., Rajkumar, R., Muwonge, R., Swaminathan,

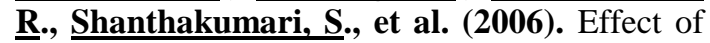
visual screening on cervical cancer incidence and mortality in Tamil

15. Sankaranarayanan R., Rajkumar, R., Esmy, P.O., Fayette, J.M., Shanthakumary,S., Frappart, L., et al. (2007). Effectiveness, safety and acceptability of 'see and treat' with cryotherapy by nurses in a cervical screening study in India. British Journal of Cancer 96(5),738-743

16. Sarian, L.O., Derchain, S.F., Naud, P., RoteliMartins, C., Longatto-Filho, A., Tatti, S., et al. (2005). Evaluation of visual inspection with acetic acid (VIA), Lugol's iodine (VILI), cervical cytology and HPV testing as cervical screening tools in Latin America. Journal of Medical Screening, 12(3),142-149.

17. Slawson D, Bennett J, \& Herman, J. (1992). Are Papanicolaou smears enough? Acetic acid washes of the cervix as adjunctive therapy: a 
HARNET study. Journal of Family Practice 35(3): 271-277.

18. Turkistanl, E.C., Sogukpınar, N., Saydam, B. K., \& Aydemir, G. (2003). Cervical Cancer Prevention and Early Detection - The Role of Nurses and Midwives. Asian Pacific Journal of Cancer Prevention, 41, 5-21.

19. University of Zimbabwe/JHPIEGO Cervical Cancer Project (2000). Visual inspection with acetic cervical-cancer screening: test qualities in primary-care settings. The Lancet, 353, 869-873.

20. Yücel, U., Çeber, E., \& Özentürk, G., (2009). Efficacy of a Training Course Given by Midwives Concerning Cervical Cancer Risk Factors and Prevention. Asian Pacific Journal of Cancer Prevention, 10(3),437-42.

21. Zimbabwe Project. Visual inspection with acetic acid for cervical-cancer screening: test qualities in a primary-care setting. University of Zimbabwe/ JHPIEGO Cervical Cancer Project. Lancet 1999;353:869-73. 